\title{
Dopamine Transport Sites Selectively Labeled by a Novel Photoaffinity Probe: ${ }^{125}$-DEEP
}

\author{
D. E. Grigoriadis, ${ }^{1}$ A. A. Wilson, ${ }^{2}$ R. Lew, ${ }^{1}$ J. S. Sharkey, ${ }^{3}$ and M. J. Kuhar ${ }^{1}$ \\ ${ }^{1}$ Neuroscience Branch, Addiction Research Center, National Institute on Drug Abuse, Baltimore, Maryland 21224, \\ 2Radiation Health, Johns Hopkins University School of Hygiene, Baltimore, Maryland 21205, and ${ }^{3}$ Department Clinical \\ Neurosciences, Western General Hospital, Edinburgh, Scotland EH4, 2XU, United Kingdom
}

The dopamine transporter was labeled using a photosensitive compound related to GBR-12909, 125/-1-[2-(diphenylmethoxy)ethyl]-4-[2-(4-azido-3-iodophenyl)ethyl]piperazine (125]-DEEP). ${ }^{125}$-DEEP bound reversibly and with high affinity to the dopamine transport protein in the absence of light and could be covalently attached to the protein following exposure to UV light. In rat striatal homogenates, ${ }^{125}$ I-DEEP was found to incorporate covalently into a protein with apparent molecular weight of 58,000 Da. The properties of this binding protein were characteristic of the dopamine transporter since covalent attachment could be inhibited by dopamine-uptake blockers with the proper pharmacological rank order of potencies. Covalent binding was also inhibited in a stereospecific manner by $(+)$ and $(-)$ cocaine, as well as other cocaine analogs. The protein was not found in the cerebellum. The dopamine transporter appears to exist in a glycosylated form since photoaffinity-labeled transport sites could adsorb to wheat germ-agglutinin and could be specifically eluted from the column by $\beta-N$-acetylglucosamine.

Dopamine reuptake is thought to be the mechanism of inactivation of released dopamine at the synapse. Dopamine uptake has been characterized by several investigators (for reviews, see Snyder, 1970; Iversen, 1973; Kuhar, 1973; Horn, 1978; Raiteri et al., 1978). More recently, the transporter has been studied by in vivo binding (Bonnet and Costentin, 1986; Andersen et al., 1987; Benmansour et al., 1987; Chagraoui, et al., 1987; Kilbourn, 1988), as well as by in vitro binding techniques (Javitz et al., 1983; Berger et al., 1985; Bonnet et al., 1986; Janowsky et al. 1986; Andersen et al., 1987). Recently, Ritz et al. (1987) and Sharkey et al. (1987) have provided evidence that the ${ }^{3} \mathrm{H}$ mazindol binding site and the ${ }^{3} \mathrm{H}-\mathrm{GBR}-12935$ binding site on the transporter have the properties of a cocaine receptor related to the reinforcing properties of cocaine.

While considerable progress has been made in the biochemical and pharmacological characterization of the dopamine transporter using tritiated selective dopamine-uptake blockers in binding studies (Van der Zee et al., 1980; Berger et al., 1985; Bonnet and Costentin, 1986; Bonnet et al., 1986; Janowsky ct al., 1986), attempts to study the molecular components of the transport site have been hindered by the lack of specific and

Received Oct. 11, 1988; revised Jan. 9, 1989; accepted Jan. 13, 1989.

Correspondence should be addressed to Dr. Michael J. Kuhar, NIDA Addiction Research Center, P.O. Box 5180, Baltimore, MD 21224.

Copyright (C) 1989 Society for Neuroscience $0270-6474 / 89 / 082664-07 \$ 02.00 / 0$ selective ligands that could label the site irreversibly. Photoaffinity labels are ligands that possess intrinsic selective affinity for a particular binding site and also contain a photolabile functional group that is capable of forming a covalent bond when exposed to UV light. For example, the development of photoaffinity probes as covalent labels for alpha- and beta-adrenergic receptors (Hess et al., 1983; Leeb-Lundberg et al., 1984; Stiles et al., 1984), as well as dopamine receptors (Amlaiky and Caron, 1985; I.ew et al., 1985; Redouane et al., 1985; Niznik et al., 1986; Grigoriadis et al., 1988), have served to elucidate the molecular structure and characteristics of these receptors. In order to study the molecular components of the dopamine transport site, it was useful to develop a high-affinity photolabel that could be used to further characterize the dopamine transporter. We now report the synthesis of a novel photoaffinity ligand, ${ }^{125}$ I-1-[2-(diphenylmethoxy)ethyl]-4-[2-(4-azido-3-iodophenyl)ethyl]piperazine ( ${ }^{125}$ I-DEEP), and its ability to selectively photolabel the dopamine transporter in rat striatum.

\section{Materials and Methods}

GBR-12909, GBR-12935, and other closely related compounds are the most selective inhibitors of dopamine uptake known (Van der Zee et al., 1980; Berger et al., 1985; Bonnet et al., 1986; Janowsky et al., 1986). Accordingly, these compounds were examined for possible sites of alteration to introduce an iodo-azido moiety, thus creating a selective, high-affinity photoaffinity radiolabeled probe. As shown by Van der Zee et al. (1980), phenyl alkyl substitutions on the piperazine ring of derivatives of 1-[2-(diphenylmethoxy)ethyl]piperazine yield potent inhibitors of dopamine uptake. Several iodo-azido compounds were synthesized and tested for uptake inhibition in the dark. The most potent analog tested was ${ }^{25}$ I-DEEP, and it was therefore selected as the ligand for subsequent studies.

\section{Synthesis of ${ }^{125} I-D E E P$}

All new compounds gave satisfactory spectral (NMR and IR) and elemental $(\mathrm{C}, \mathrm{H}, \mathrm{N})$ analyses. Purifications and analyses of ${ }^{125} \mathrm{I}$-containing radioactive mixtures were performed on an HPLC system composed of a Rheodyne 7125 injector, 2 Waters $510 \mathrm{EF}$ pumps, a UV detector (Waters 481), and an Ortec flow radioactivity detector. Peak areas were measured using Hewlett-Packard 3990A recording integrators. Sodium ${ }^{125}$ I-iodide was obtained from Amersham Corp. (IMS-30 or IMS-300).

1-[2-(Diphenylmethoxy)ethyl]-4-[2-(4-nitrophenyl)ethyllpiperazine. A solution of 4-nitrobenzyl bromide $(2.0 \mathrm{gm}, 8.7 \mathrm{mmol})$ 1-[2-(dipheny]methoxy)ethyl]-piperazine $(2.58 \mathrm{gm}, 8.7 \mathrm{mmol})$, and tetramethyl piperidine $(3 \mathrm{ml})$ in acetonitrile $(20 \mathrm{ml})$ was stirred under reflux for $6 \mathrm{hr}$. Ether $(50 \mathrm{ml})$ was added to the cooled solution and the mixture filtered. The filtrate was evaporated to dryness and the residue chromatographed on silica [EtOAc:Pet.ether: $\mathrm{Et}_{3} \mathrm{~N}, 400: 100: 25(\mathrm{vol} / \mathrm{vol})$ ] to give a pale yellow oil $(2.7 \mathrm{gm}, 70 \%)$.

1-[2-(Diphenylmethoxy)ethyl]-4-[2-(4-aminophenyl)ethyllpiperazine (Fig. 1, 1). A mixture of 1-[2-(diphenylmethoxy)ethyl]-4-[2-(4-nitrophenyl)ethyl]piperazine $(2.5 \mathrm{gm}, 5.6 \mathrm{mmol})$ and $5 \%$ palladium on char- 
coal $(0.4 \mathrm{gm})$ in ethanol $(30 \mathrm{ml})$ was stirred under 1 atmosphere of hydrogen for $3 \mathrm{hr}$ and then filtered. The filtrate was evaporated to dryness to leave a colorless oil $(2.31 \mathrm{gm}, 99.2 \%)$. The trihydrochloride salt was recrystallized from ethanol.

1-[2-(diphenylmethoxy)ethyl]-4-[2-(4-amino-3-iodophenyl)ethyl]piperazine. A solution of iodine monochloride $(0.24 \mathrm{gm}, 1.45 \mathrm{mmol})$ in acetic acid $(1.3 \mathrm{ml})$ was added slowly to a stirred solution of $1-[2-$ (diphenyl-methoxy)ethyl]-4-[2-(4-aminophenyl)ethyl]piperazine (0.6 gm, $1.44 \mathrm{mmol})$ in acetic acid $(3.3 \mathrm{ml})$ under argon at room temperature. After $15 \mathrm{~min}$, the reaction was quenched by the addition of saturated aqueous $\mathrm{Na}_{2} \mathrm{CO}_{3}$. The mixture was extracted with ether $(2 \times 20 \mathrm{ml})$, which was washed with $20 \mathrm{ml}$ aqueous $\mathrm{Na}_{2} \mathrm{~S}_{2} \mathrm{O}_{3}(1 \mathrm{M})$ and $20 \mathrm{ml}$ brine, dried $\left(\mathrm{Na}_{2} \mathrm{SO}_{4}\right)$, and filtered. The resultant red oil was chromatographed on silica [EtOAc:Pet.ether:Et $\left.{ }_{3} \mathrm{~N}, 350: 100: 25(\mathrm{vol} / \mathrm{vol})\right]$ to give the product as a pale yellow oil $(0.51 \mathrm{gm}, 65 \%)$.

${ }^{127}$ I-DEEP 1-[2-(diphenylmethoxy)ethyl]-4-[2-azido-3-iodophenyl)ethyl]piperazine ( $\left.{ }^{227} I-D E E P\right)$. An ice-cold stirred solution of 1-[2-(diphenylmethoxy)ethyl]-4-[2-(4-amino-3-iodophenyl)ethyl]piperazine $(0.37 \mathrm{gm}, 0.68 \mathrm{mmol})$ in aqueous acetic acid $(28 \mathrm{ml}, 3 \mathrm{M})$ and methanol ( $8 \mathrm{ml}$ ) was treated with a solution of sodium nitrite $(65 \mathrm{mg}, 0.94 \mathrm{mmol})$ in water $(2 \mathrm{ml})$ dropwise. The mixture was stirred for $20 \mathrm{~min}$ and a solution of sodium azide $(63 \mathrm{mg}, 0.97 \mathrm{mmol})$ in water $(2 \mathrm{ml})$ added dropwise. The solution was stirred at room temperature for $20 \mathrm{~min}$ and conc. aqueous $\mathrm{NH}_{4} \mathrm{OH}(8 \mathrm{ml})$ was added cautiously. The mixture was extracted with $\mathrm{CH}_{2} \mathrm{Cl}_{2}(2 \times 20 \mathrm{ml})$, dried $\left(\mathrm{Na}_{2} \mathrm{SO}_{4}\right)$, and filtered. Evaporation of the solvent left an oil that was chromatographed on silica [EtOAc:Pet.ether: $\left.\mathrm{Et}_{3} \mathrm{~N}, 250: 250: 25(\mathrm{vol} / \mathrm{vol})\right]$ to give the product as a pale brown oil $(0.3 \mathrm{gm}, 77 \%)$.

${ }^{125}$ I-1-[2-(diphenylmethoxy)ethyl]-4-[2-(4-azido-3-iodophenyl)ethyl]piperazine ([125IJDEEP) (Figs. 1, 2). This was prepared from 1-[2-(diphenylmethoxy)ethyl]-4-[2-(4-aminophenyl)ethyl]piperazine using a 3-step, 1-pot method for the conversion of an aminophenyl moiety into an ${ }^{125}$ I-labeled phenylazide. Semipreparative reverse-phase HPLC was used to isolate ${ }^{125}$ I-DEEP. The radiochemically pure product $(>99 \%)$ was obtained in $45-50 \%$ isolated radiochemical yield from starting ${ }^{125} \mathrm{I}-$ iodide and had identical chromatographic (HPLC and TLC) properties to authentic ${ }^{127}$ I-DEEP. Specific activities were determined by an HPLC method (Wilson et al., 1986) to be between 800 and $1500 \mathrm{Ci} / \mathrm{mmol}$ (refer to Fig. 1).

${ }^{3} \mathrm{H}$-GBR-12935 was obtained through New England Nuclear (Boston, MA). All other standard chemicals and reagents were obtained through either Sigma Chemical Co. (St. Louis, MO) or Bio-Rad (Richmond, CA). Wheat germ agglutinin-Sepharose 6B was purchased from Pharmacia LKB (Pleasant Hill, CA).

\section{Membrane preparation}

Male Sprague-Dawley rats (Harlan Ind, IN) were killed by decapitation, and the brains werc quickly removed on icc. Striata werc dissected and quick-frozen in liquid nitrogen and stored whole at $-70^{\circ} \mathrm{C}$ until day of assay. On the day of assay, striata were thawed, weighed, and homogenized in $10 \mathrm{ml}$ buffer containing $50 \mathrm{mM}$ Tris- $\mathrm{HCl}, 120 \mathrm{mM} \mathrm{NaCl}, 5$ $\mathrm{mm} \mathrm{KCl}, 1 \mathrm{~mm}$ phenylmethylsulfonyl fluoride (PMSF), and $1 \mu \mathrm{g} / \mathrm{ml}$ leupeptin (assay buffer) using a Brinkmann polytron (setting 6) for 20 sec. Membranes were centrifuged at $20,000 \mathrm{rpm}$ for $10 \mathrm{~min}$ at $4^{\circ} \mathrm{C}$, the supernatant discarded, and the pellets resuspended in $10 \mathrm{ml}$ buffer and centrifuged again at $20,000 \mathrm{rpm}$ for $10 \mathrm{~min}$ at $4^{\circ} \mathrm{C}$. The final pellets were resuspended in the above buffer to a working concentration of 20 $\mathrm{mg} / \mathrm{ml}$ original wet weight (o.w.w.) and kept on ice until use.

\section{Reversible binding of ${ }^{225} I-D E E P$ to rat striatal homogenates}

Reversible binding of ${ }^{125}$ I-DEEP was performed in the dark using a centrifugation binding assay. Typically, $100 \mu \mathrm{l}$ of the membrane preparation was added to tubes containing either ${ }^{3} \mathrm{H}-\mathrm{GBR}-12935$ (final concentration, $1 \mathrm{nM}$ ) or ${ }^{125}$ I-DEEP (final concentration, 1-2 nM), as well as $100 \mu \mathrm{l}$ of the competing ligands in a final volume of $1.0 \mathrm{ml}$. Incubations were carried out on ice $\left(0-4^{\circ} \mathrm{C}\right)$ for $60 \mathrm{~min}$ and the reaction terminated by centrifugation in a Beckman microfuge for $10 \mathrm{~min}$ at $12,000 \mathrm{rpm}$. Aliquots of the supernatant $(100 \mu \mathrm{l})$ were removed and monitored for radioactivity in order to determine the amount of "free" ligand present in the tubes. The pellets were washed twice by centrifugation and counted for bound radioactivity in an LKB gamma-counter at $80 \%$ efficiency for ${ }^{125}$ I-experiments or a Beckman 3801 liquid-scintillation counter at $50 \%$ efficiency for tritium. Data analysis was performed using the nonlinear least-squares curve-fitting program LIGAND (Munson and Rod-

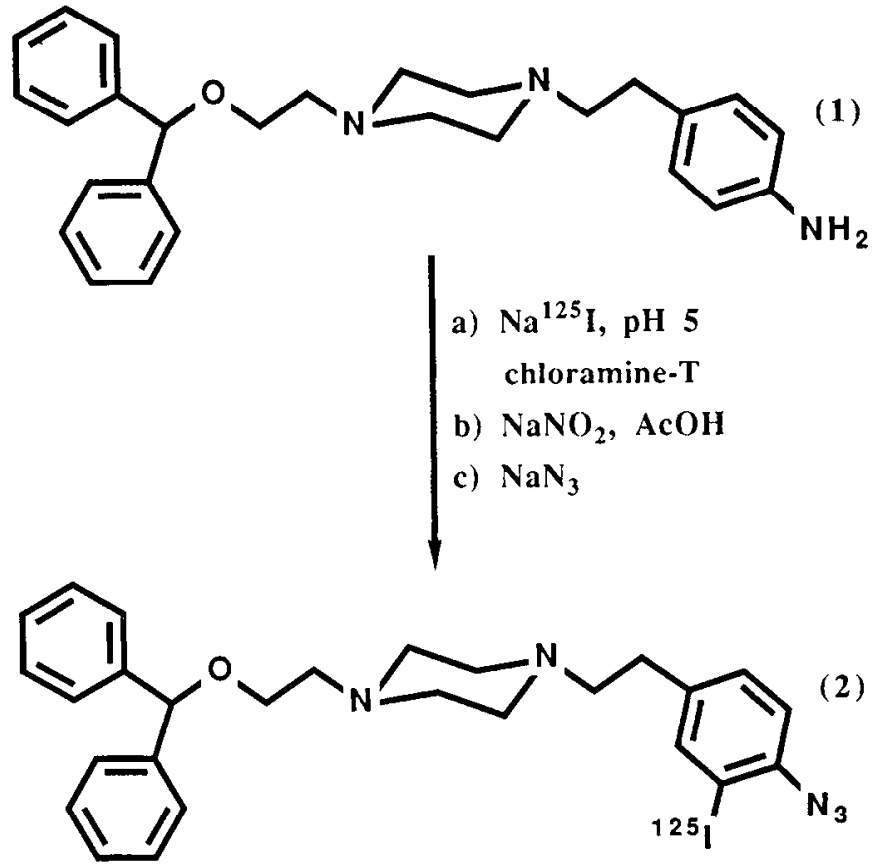

Figure 1. Synthesis of ${ }^{125}$ I-DEEP. ${ }^{125}$ I-1-[2-(diphenylmethoxy)ethyl]4-[2-(4-azido-3-iodophenyl)ethyl]piperazine ( ${ }^{125}$ I-DEEP; 2) was prepared from the corresponding 4-aminoethyl compound ( 1 ) by a 3-step, 1-pot method for the conversion of an aminophenyl moiety into an ${ }^{125}$ Ilabeled phenylazide. Semipreparative reverse-phase HPLC was used to isolate ${ }^{125}$ I-DEEP. The radiochemically pure product $(>99 \%)$ was obtained in $45-50 \%$ isolated radiochemical yields from starting ${ }^{125} \mathrm{I}$-iodide and had identical (HPLC and TLC) properties to authentic ${ }^{125}$ I-DEEP. Specific activities were determined by an HPLC method (Wilson et al., 1986) to be between 800 and $1500 \mathrm{Ci} / \mathrm{mmol}$.

bard, 1980). Protein determinations were carried out by the method of Lowry et al. (1951) with BSA as the standard.

\section{Covalent photoaffinity labeling of striatal membranes}

For the photoaffinity labeling of rat striatal homogenates, membranes were incubated with ${ }^{125}$ I-DEEP (final concentration, 1-2 nM) as described above for the reversible studics. Following the $60 \mathrm{~min}$ incubation at $4^{\circ} \mathrm{C}, 1 \mathrm{ml}$ aliquots were placed in $35 \times 10 \mathrm{~mm}$ petri dishes, placed $11 \mathrm{~cm}$ below an $85 \mathrm{~W} \mathrm{Hg}$ lamp (Thomas Scientific, NJ), and exposed to direct UV light for $40 \mathrm{sec}$ without stirring (path length or depth of membrane suspension was approximately 3-4 mm). Membranes were then transferred directly into clean eppendorf tubes, washed twice with assay buffer by centrifugation, and processed for electrophoresis as decribed below.

\section{$S D S-P A G E$}

Samples for electrophoresis were resuspended in $120 \mu 1$ SDS-sample buffer containing $50 \mathrm{~mm}$ Tris- $\mathrm{HCl}, 2 \%$ SDS, $10 \%$ glycerol, $5 \% \beta$-mercaptoethanol, and $0.005 \%$ bromphenol blue $\left(\mathrm{pH} 6.8,22^{\circ} \mathrm{C}\right)$ and incubated for $60 \mathrm{~min}$ on a vortex mixer. Following the incubation, $100 \mu \mathrm{l}$ of the soluble sample was loaded on a discontinuous slab gel ( $6 \%$ stacking and 10 or $12 \%$ running) according to the method of Laemmli (1970). An equivalent amount of protein was loaded onto each lane $(200-400$ $\mu \mathrm{g})$ and typically run overnight at a constant current of 10-20 mA. Boiling the samples for 10 min prior to electrophoresis did not alter the labeling pattern of ${ }^{125}$ I-DEEP to membrane homogenates (data not shown). Prestained molecular-weight protein standards (Sigma) were included on each gel and used to calculate the apparent molecular weights of the labeled species. Following electrophoresis, the gels were dried (for autoradiography) using a Bio-Rad slab gel drier or cut into lanes, sliced into $2 \mathrm{~mm}$ slices and monitored for radioactivitiy. For autoradiography, dried gels were exposed to Kodak X-AR5 film using Lightning-Plus intensifying screens at $-70^{\circ} \mathrm{C}$ for a period of $5-10 \mathrm{~d}$. 
Figure 2. Competition of ${ }^{3} \mathrm{H}-\mathrm{GBR}$ 12935 and ${ }^{127}$ I-DEEP in rat striatal homogenates. ${ }^{127}$ I-DEEP competed for ${ }^{3} \mathrm{H}$ GBR-12935 (final concentration, $1 \mathrm{nM}$ ) under nonphotolyzing conditions. Rat striatal homogenates (final concentration, $2 \mathrm{mg} / \mathrm{ml}$ wet weight) were incubated for $60 \mathrm{~min}$ at $0-4^{\circ} \mathrm{C}$ in a tinal volume of $1 \mathrm{ml}$, and the reaction was terminated by centrifugation. Aliquots $(100 \mu)$ of the supernatant were counted to determine the "free" concentration of ligand present in each tube. Pellets were washed twice without resuspension with ice-cold buffer by centrifugation and counted for bound radioactivity. Total binding was typically 20,000 DPM, while nonspecific binding was approximately $7000 \mathrm{DPM}$, representing a $65 \%$ signal to noise ratio. $\mathrm{IC}_{x 1}$ values were estimated by the nonlinear least-squares curve-fitting program LIGAND (Munson and Rodbard, 1980) and are given in the text. The above experiment was performed in triplicate and is representative of $2 \mathrm{in}$ dependent determinations with similar results.

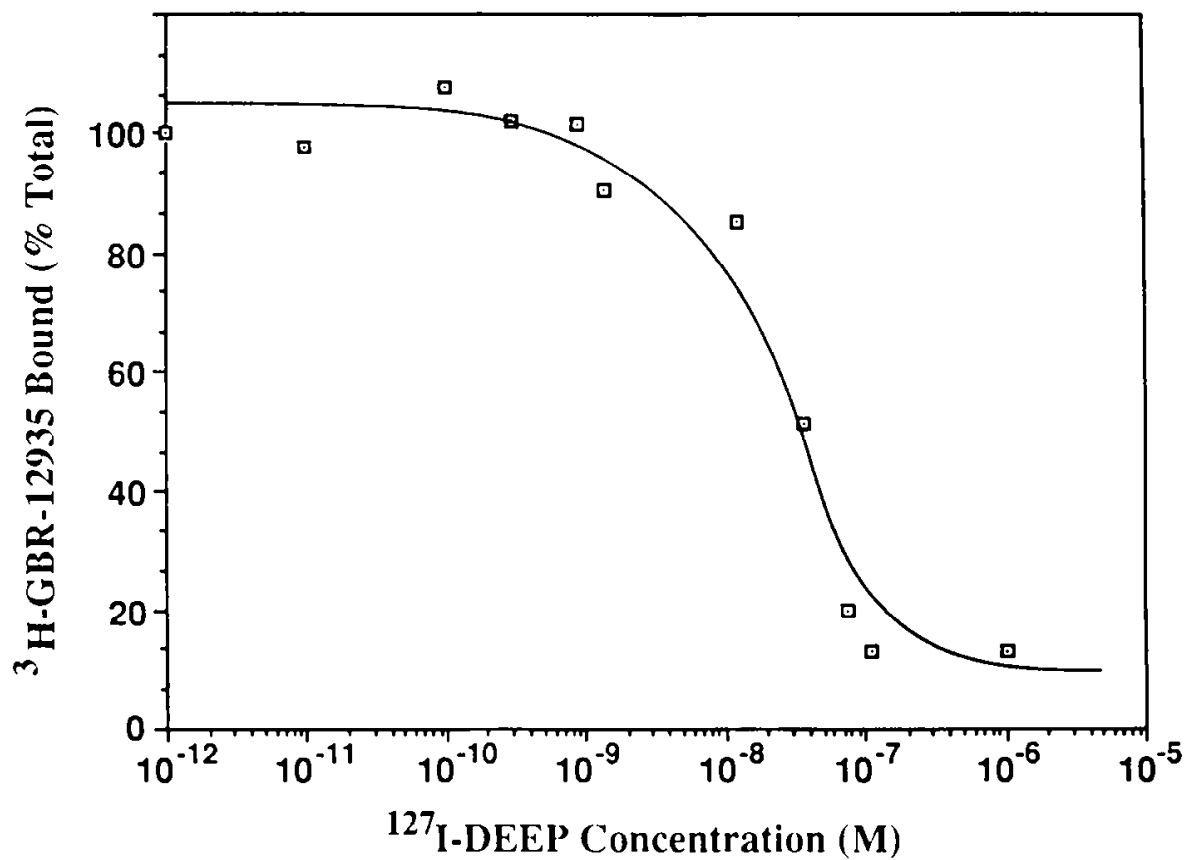

\section{Wheat germ agglutinin (WGA) affinitv chromatography}

Affinity chromatography on WGA-Sepharose was performed on membranes that were photolabeled as described above. Following photolysis, the membranes were washed by centrifugation and resuspended in assay buffer containing digitonin (Waco, TX) at a final concentration of $1 \%$. Samples were incubated at $4^{\circ} \mathrm{C}$ for $60 \mathrm{~min}$ and centrifuged at 110,000 $\times g$ for $60 \mathrm{~min}$. The supernatant was passed through a Millex $0.22 \mu \mathrm{m}$ filter (Bedford, MA), loaded onto $20 \mathrm{ml}$ of WGA-Sepharose beads in a column equilibrated with assay buffer plus $0.1 \%$ digitonin and allowed to incubate on the column for $45 \mathrm{~min}$ at $4^{\circ} \mathrm{C}$. Following the incubation, the column was washed in $100 \mathrm{ml}$ ( 5 column volumes) assay buffer plus $0.1 \%$ digitonin before elution. Elution was performed in the same buffer as above with $200 \mathrm{~mm} \beta-N$-acetylglucosamine (GlcNac) at $1 \mathrm{ml} / \mathrm{min}$ flow rate and fractions collected and monitored for radioactivity.

\section{Results}

Reversible binding analvsis of DEEP with rat striatal membranes

In order to determine the binding characteristics of DEEP, unlabeled ( ${ }^{227} \mathrm{I}$-DEEP) DEEP was competed for ${ }^{3} \mathrm{H}-\mathrm{GBR}-12935$

Table 1. Inhibitory order of potencies of drugs on ${ }^{125}$ I-DEEP binding to rat striatal membranes

\begin{tabular}{lc} 
Compound & $\begin{array}{l}K, \\
\text { (nM) }\end{array}$ \\
\hline GBR-12909 & 36.3 \\
Mazindol & 20.1 \\
Nomifensine & 138.2 \\
Citalopram & $>10,000$ \\
Desipramine & $>10,000$
\end{tabular}

The data show that competition of various compounds for the reversible binding of ':'I-DEEP (final concentration, 1-2 nM) exhibits the proper pharmacological rank-order profile for the dopamine transporter and corresponds with the pharmacology observed on the 58,000 Da protein covalently labcled and demonstrated in Figure 4. All compounds inhibited the binding of 1:I-DEEP to striatal membrane homogenates in a monophasic manner, demonstrating binding to a single class of binding sites. All curves were performed in triplicate using the centrifugation assay described in Materials and Methods and analyzed using the nonlinear least-squares curve-fitting program LiGAND (Munson and Rodbard, 1980). binding ( $1 \mathrm{nM}$ ) in rat striatal homogenates using GBR-12909 as a blank, under nonphotolyzing conditions (in the dark). ${ }^{127} \mathrm{I}-$ DEEP was found to bind with high affinity to the dopamine transport protein in rat striatal homogenates with an apparent

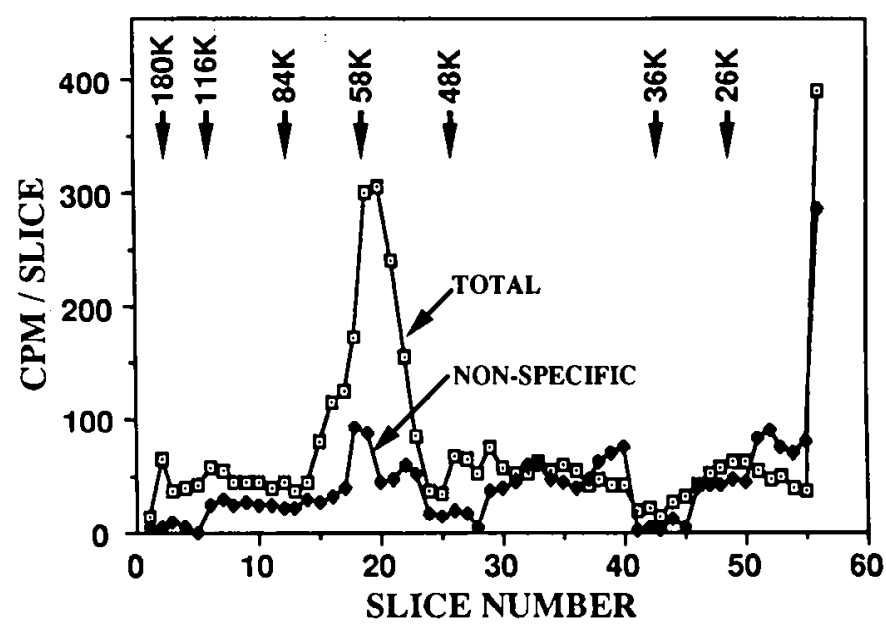

Fïgure 3. SDS-PAGE labeling pattern of photolabeled dopamine transporter using 1:ST-DEEP. Membranes werc incubated in the dark (final concentration, $2 \mathrm{mg} / \mathrm{ml} \mathrm{o.w.w.)} \mathrm{with} \mathrm{1-2} \mathrm{nM}{ }^{12 s} \mathrm{I}$-DEEP for $60 \mathrm{~min}$ at $0-4^{\circ} \mathrm{C}$. Nonspecific binding was determined in the presence of $1 \mu \mathrm{M}$ GBR-12909. Following the incubation, $1 \mathrm{ml}$ aliquots were exposed to UV light for $40 \mathrm{sec}$ and centrifuged for $15 \mathrm{~min}$ at $12,000 \mathrm{rpm}$. The pellets were washed twice by centrifugation, solubilized in SDS sample buffer, and processed for electrophoresis. Gels were typically run overnight at a constant current of 10-20 mA and the lanes cut into $2 \mathrm{~mm}$ slices and monitored for radioactivity in a gamma counter. Typically, $25,000-30,000 \mathrm{cpm}$ were loaded onto each lane. The efficiency of covalent labeling was calculated to be approximately $5-6 \%$ of specific bound DEEP. Prestained molecular-weight standards were run on cach gel and used to estimate the molecular weights of the bound species. In rat striatum, a major protein with an apparent molecular weight of 58,000 Da was labeled and could be inhibited by the addition of $1 \mu \mathrm{M}$ GBR12909. 


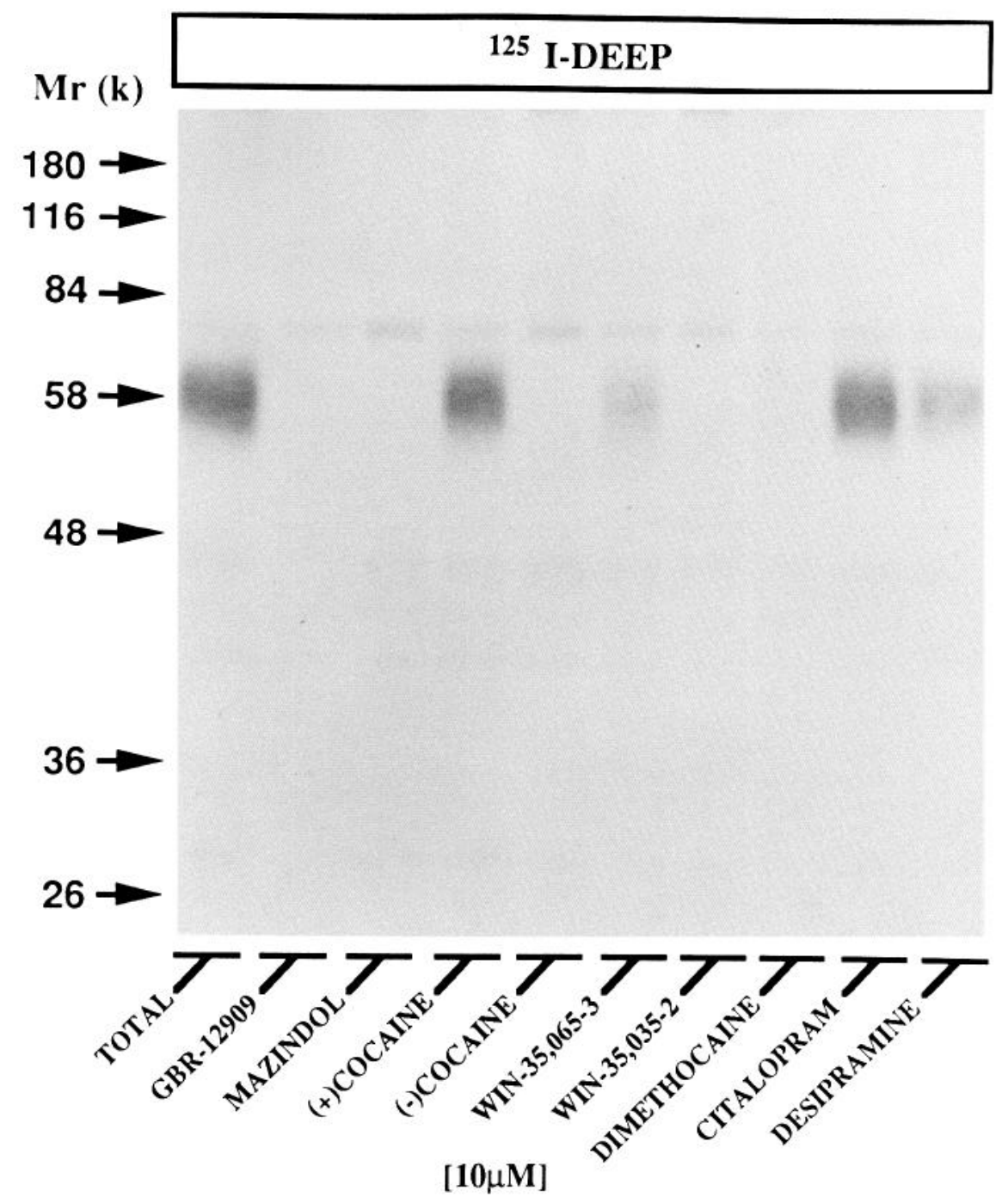

Figure 4. Pharmacological specificity of ${ }^{12}$ 'I-DEEP labeled proteins. Membranes were prepared as described in Materials and Methods and Figure 3, and incubated in the presence of various compounds. The results demonstrate that the labeled protein migrating at 58,000 Da represents the dopaminetransporter binding site. Other nonspecifically labeled proteins were apparent but were not inhibited by any of the dopaminergic ligands tested. Similarly, the serotonin-uptake blocker citalopram and the norepinephrine-uptake inhibitor desipramine could not inhibit the covalent incorporation of 12 I-DEEP to any of the proteins labeled in striatal membrane homogenates. The major labeled band at $58,000 \mathrm{Da}$ was defined by both rank-order potencies and stereospecificity to be the dopamine transporter. This experiment is representative of 4 independent studies that yielded identical results. affinity $\left(K_{t}\right)$ of 10-20 nм (see Fig. 2). Figure 2 also demonstrates that the binding was monophasic and thus represented binding to a single class of sites. These data are in agreement with the values obtained from direct saturation isotherms using ${ }^{125}$ I-DEEP (data not shown).

\section{Pharmacological specificity of "'S-DEEP binding}

Various ligands were competed for ${ }^{125}$ I-DEEP binding (1-2 nM final concentration), again under nonphotolyzing conditions, and their apparent $K$, values are listed in Table 1. Reversible binding of ${ }^{125}$ I-DEEP revealed that GBR-12909, mazindol, and nomifensine could inhibit the binding with $K$, values similar to those reported for ${ }^{3} \mathrm{H}-\mathrm{GBR}-12935$ binding to the dopamine transport site (Andersen, 1987). The serotonin transport blocker citalopram, as well as the adrenergic-uptake inhibitor desipramine, had very little effect on the binding of ${ }^{125}$ I-DEEP even at high concentrations.

\section{Covalent photoincorporation of ${ }^{125} I-D E E P$ to rat striatal membranes}

${ }^{125}$ I-DEEP was photoincorporated into rat striatal membrane homogenates by exposure to UV light. The membranes were solubilized in SDS sample buffer and electrophoresed on SDS- polyacrylamide gels as described in Materials and Methods. ${ }^{125} \mathrm{I}-$ DEEP was mainly incorporated into a protein of molecular weight $58,000 \mathrm{Da}$ as observed by direct measurement of radioactivity in the gel (Fig. 3). Binding to this protein was blocked by the addition of GBR-12909, a selective dopamine-uptake blocker. Autoradiograms of gels also revealed that ${ }^{125}$ I-DEEP was being incorporated into other proteins but to a lesser extent; these proteins had apparent molecular weights of 70,000,45,000, 30,000 , and <20,000 Da (Figs. 4, 5).

In order to further demonstrate that the protein band labeled at 58,000 had pharmacological properties characteristic of the dopamine transport protein, various compounds were incubated with ${ }^{125}$ I-DEEP prior to photolysis and the membranes solubilized in SDS-sample buffer and processed for electrophoresis. As clearly shown in Figure 4 , in the absence of any competing ligands (total), ${ }^{125}$ I-DEEP was incorporated into a major labeled protein migrating with an apparent molecular weight of $58,000 \mathrm{Da}$. In the presence of $10 \mu \mathrm{M}$ GBR-12909, 10 $\mu \mathrm{M}$ mazindol, or $10 \mu \mathrm{M}$ dimethocaine, photoincorporation into this protein was completely inhibited. $(+)$ Cocaine, $10 \mu \mathrm{M}$, did not inhibit the incorporation of ${ }^{12}$ I-DEEP, while the same concentration of $(-)$ cocaine was sufficient to block the covalent attachment. Similarly WIN-35,065-2 could inhibit the incor- 
Figure 5. Covalent incorporation of ${ }^{125}$ I-DEEP in striatal and cerebellar homogenates. Rat striatal and cerebellar homogenates were prepared in parallel, incubated with 1-2 $\mathrm{nM}^{125}$ I-DEEP in the presence or absence of the compounds listed above. Assays were conducted for $60 \mathrm{~min}$ at $0-4^{\circ} \mathrm{C}$ and photolyzed as described under Materials and Methods. The autoradiogram shown is overexposed to bring out minor peaks of radioactivity in order to more thoroughly assess specificity; the bulk of radioactivity, however, is in the $58,000 \mathrm{Da}$ band, as shown in Figure 3. Although identical photoincorporation of ${ }^{125} \mathrm{I}$ DEEP to many nonspecific proteins was evident in both tissues, there was a conspicuous absence of any labeled proteins in the cerebellum with an apparent molecular weight of 58,000 Da.

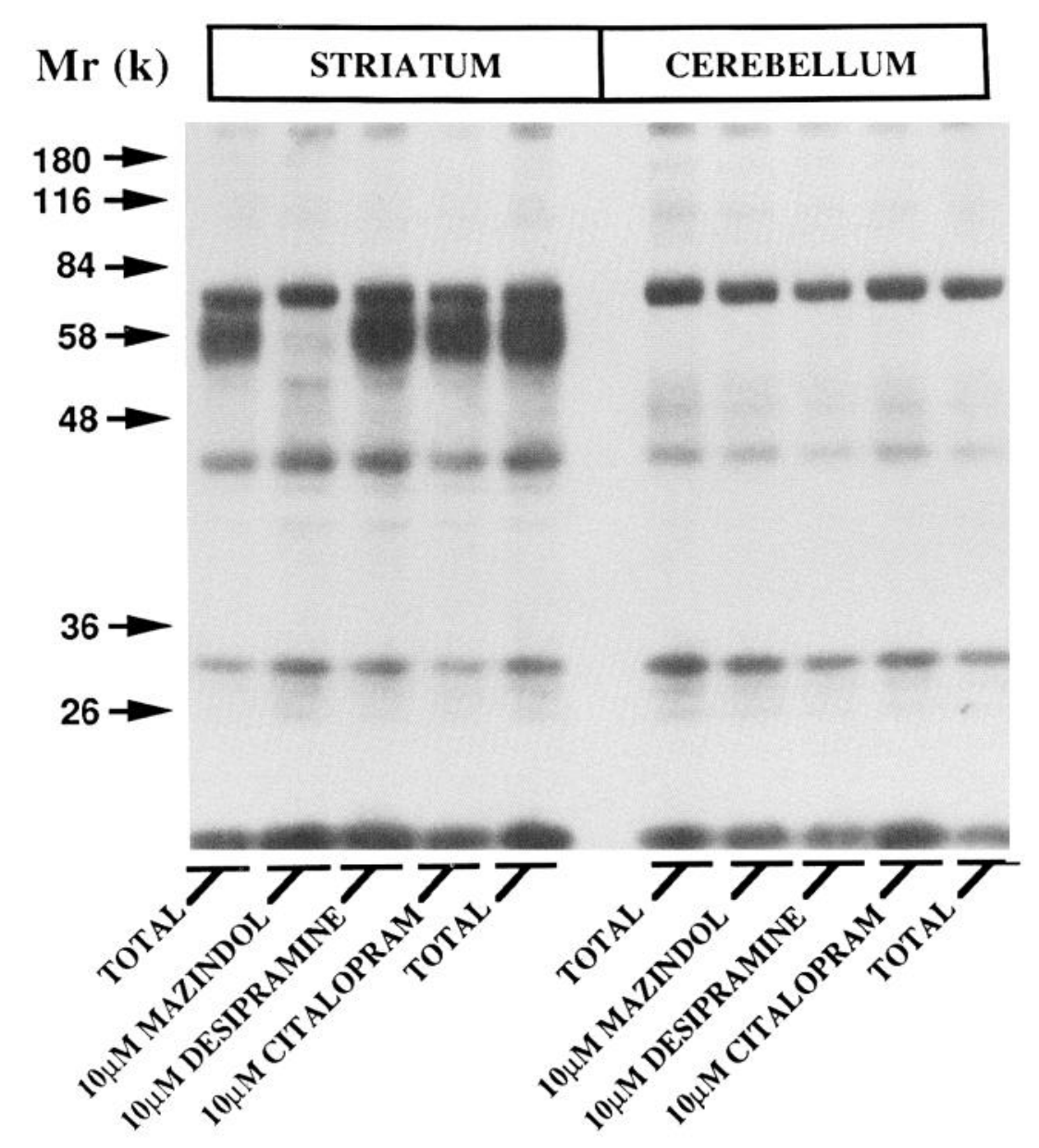

poration of ${ }^{125}$ I-DEEP, while WIN-35,065-3 was ineffective. In other experiments, we also found that $1 \mu \mathrm{M}$ GBR-12909, $1 \mu \mathrm{M}$ mazindol, and $1 \mu \mathrm{M}$ nomifensine inhibited photoincorporation of ${ }^{125} \mathrm{I}$-DEEP into the $58,000 \mathrm{Da}$ protein (data not shown). These data demonstrate that the covalent labeling of the dopamine transport protein by ${ }^{125} \mathrm{I}$-DEEP was stereospecific and could be inhibited by the proper pharmacological rank-order profile of compounds (Ritz et al., 1987) expected for the dopamine transporter. The serotonergic uptake blocker citalopram and the adrenergic uptake inhibitor desipramine were ineffective in blocking the covalent attachment of ${ }^{125}$ I-DEEP to the dopamine transport binding site (Fig. 4).

In order to further establish that ${ }^{125}$ I-DEEP was specifically labeling the dopamine transport protein, we prepared membrane homogenates from rat cerebellum, photolyzed them in the presence of ${ }^{125}$ I-DEEP (1-2 nM final concentration) with or without competing ligands, and compared the labeling pattern on SDS gels to that observed in the rat striatum. Figure $5 \mathrm{dem}$ onstrates that although identical nonspecifically labeled proteins appear both in the cerebellum as well as the striatum, the 58,000 Da protein that exhibits a pharmacological profile of the dopamine transport protein is not evident in the cerebellum. It is interesting to note that the nonspecifically labeled proteins in the cerebellum could not be inhibited by either the serotonergic uptake blocker citalopram or the adrenergic uptake blocker desipramine (Fig. 5), thus strengthening the evidence presented that ${ }^{125}$ I-DEEP was not labeling other monoaminergic uptake systems.

\section{Adsorption of ${ }^{125} I-D E E P$ labeled protein to $W G A$-Sepharose $6 B$}

To further elucidate some of the molecular properties of the dopamine transport site, photolabeled proteins were solubilized in $1 \%$ digitonin and adsorbed onto WGA-Sepharose as described in Materials and Methods. We found that covalently labeled proteins could be adsorbed and specifically eluted from WGA using $200 \mathrm{~mm}$ of the sugar $\beta$ - $N$-acetylglucosamine. Figure 6 illustrates the complete wash and elution profiles of ${ }^{125} \mathrm{I}$-DEEPlabeled transport proteins from WGA. The figure demonstrates that following $100 \mathrm{ml}$ ( 5 column volumes) of wash, there was very little detectable radiolabel in the fractions, although 90$95 \%$ of the radioactivity loaded onto the column was removed during the wash. Following the onset of elution with $200 \mathrm{~mm}$ GlcNac, there was robust and rapid desorption of labeled material off the column, with more than $90 \%$ of the protein removed in one column volume $(20 \mathrm{ml})$ following the exclusion of the first $10 \mathrm{ml}$ of elution. This indicates that the protein contains either $\mathrm{N}$-acetylglucosamine residues or terminal sialic acid residues. Further studies will be required to determine the quantity and nature of the glycosylation sites on the dopamine transport protein.

\section{Discussion}

GBR 12909 and related compounds have been shown to be highly specific inhibitors of the dopamine transport system (Van der Zee et al., 1980; Heikkila and Manzino, 1984; Bonnet et 


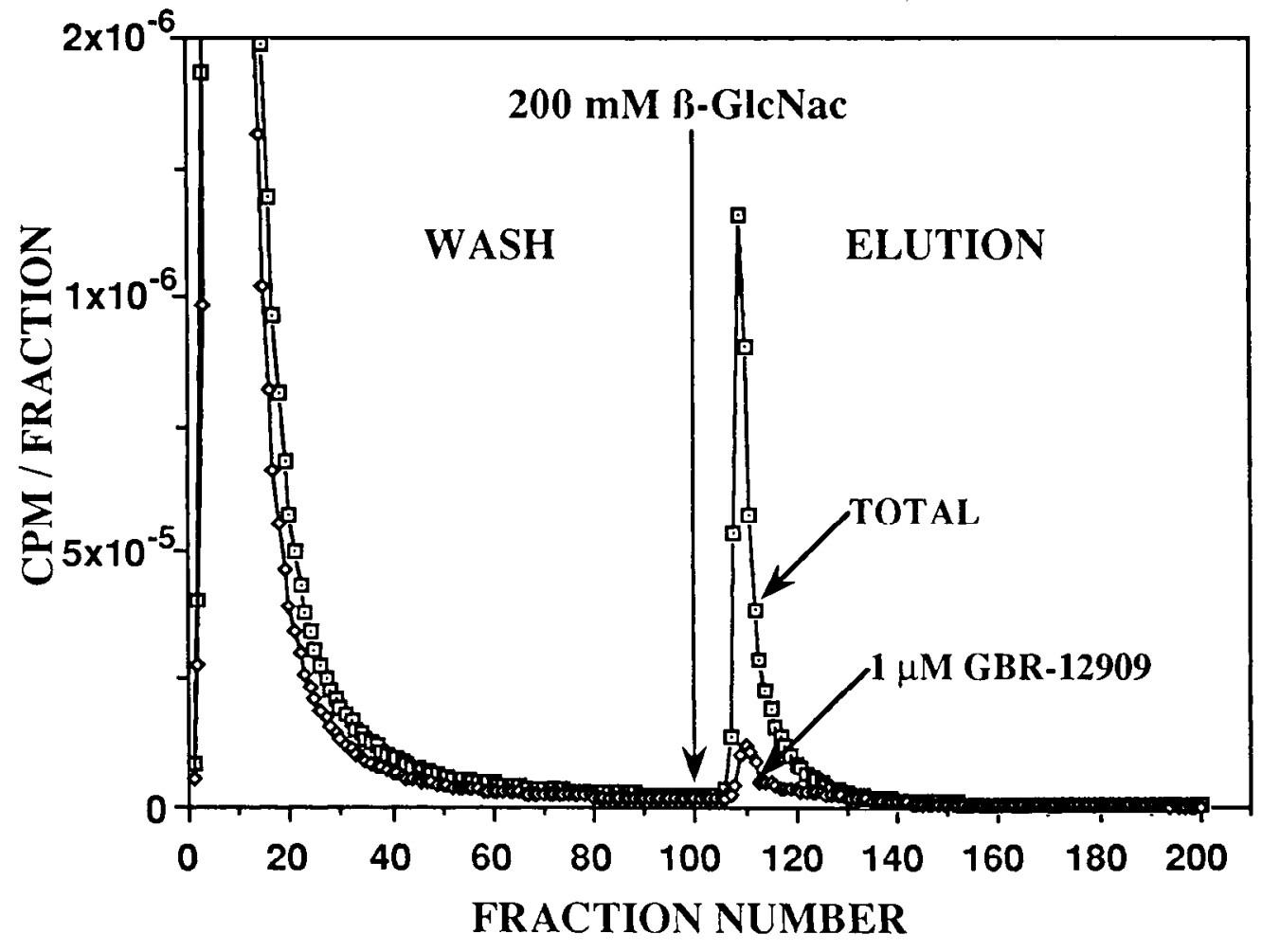

Figure 6. Wheat germ agglutinin-affinity chromatography of ${ }^{125}$ I-DEEP-labeled proteins. Membrane homogenates were prepared and photolabeled as described. Following photolysis, the membranes were washed twice by centrifugation and resuspended in assay buffer (final concentration, $100 \mathrm{mg}$ wet weight $/ \mathrm{ml}$ ) with $1 \%$ digitonin and solubilized for $45 \mathrm{~min}$ at $0-4^{\circ} \mathrm{C}$ in a final volume of $10 \mathrm{ml}$. Solubilized proteins were loaded onto a $20 \mathrm{ml}$ column of WGA-Sepharose and allowed to incubate on the column for $45 \mathrm{~min}$. The column was washed at a flow rate of 1 $\mathrm{ml} / \mathrm{min}$ with 5 column volumes of buffer $(100 \mathrm{ml})$ containing $0.1 \%$ digitonin. The column was eluted at a flow rate of $0.5 \mathrm{ml} / \mathrm{min}$ with assay buffer containing $0.1 \%$ digitonin and $200 \mathrm{~mm} \beta-N$ acetylglucosamine. ${ }^{125}$ I-DEEP labeled proteins were specifically eluted in the first $10 \mathrm{ml}$ of elution. This experiment was repeated with identical results. al., 1986; Andersen, 1987; Chagraoui et al., 1987). ${ }^{3} \mathrm{H}-\mathrm{GBR}-$ 12935 has been shown to be a potent and highly selective ligand for binding to dopamine transporters (Berger et al., 1985; Janowsky et al., 1986; Andersen et al., 1987). Since it has been determined that the piperazine-containing portion of the GBR compounds could be altered and yet retain high-affinity binding to and specificity for the transporter (van der Zee et al., 1980), we utilized the strategy of developing an iodo-azido moiety at this portion of the molecule. After examining several iodo-azido-GBR derivatives, ${ }^{125}$ I-DEEP was selected as a high-affinity specific ligand for the dopamine transporter.

Under reversible conditions, ${ }^{127} \mathrm{I}$-DEEP inhibited the binding of ${ }^{3} \mathrm{H}-\mathrm{GBR}-12935$ with a $K_{i}$ value of 10-20 nM that corresponded closely to the affinity of a related molecule, GBR-12909. The affinity of ${ }^{125} \mathrm{I}$-DEEP determined by direct saturation isotherms was found to be slightly higher $K_{D}=2 \mathrm{nM}$ ) than the $K_{i}$ value obtained from competition experiments. The pharmacological rank order of potencies of compounds that inhibited DEEP binding was found to be characteristic of the dopamine transporter. GBR-12909 had approximately the same affinity as mazindol, while both had greater affinity than nomifensine. The serotonin-uptake blocker citalopram and the noradrenergic uptake inhibitor desipramine were both without effect. These data indicate that so long as the integrity of the azido moiety remains intact (in the dark), ${ }^{125}$ I-DEEP interacts with the dopamine transport site with the same reversible characteristics as any of the established GBR analogs.

Following photolysis, when the incubation mixtures were exposed to UV light under conditions in which specific binding of ${ }^{125} \mathrm{I}$-DEEP to dopamine transporters was occurring, we observed incorporation of radiolabeled drug into various membrane proteins. In order to obtain an initial estimate of the molecular weight of the dopamine transporter, photolabeled membrane proteins were subjected to SDS-PAGE. The gels were sliced into $2 \mathrm{~mm}$ slices and monitored for incorporated radioactivity. The major peak of incorporation occurred at an apparent molecular weight of 58,000 Da, and $1 \mu \mathrm{M}$ GBR-12909 inhibited this incorporation, suggesting that the protein labeled at $58,000 \mathrm{Da}$ was the dopamine transporter. Conclusive evidence that the 58,000 Da protein did indeed represent the dopamine transporter was obtained from the pharmacological profile of the photoincorporated proteins.

In the presence of various compounds used to identify the dopamine-uptake site, the incorporation of ${ }^{125}$ I-DEEP could be inhibited by compounds such as GBR-12909, mazindol, nomifensine, dimethocaine, (-)cocaine, and the cocaine analog WIN-35,065-2. Furthermore, the 58,000 Da covalently labeled protein exhibited stereoselectivity with respect to $(+)$ and $(-)$ cocaine, as well as the stereoisomers of the cocaine analogs WIN-35,065-2 and WIN-35,065-3. In addition to the pharmacological data, photolyzcd membranes of rat cerebellum showed a conspicuous absence of any labeled protein with a molecular weight of 58,000 $\mathrm{Da}$, strongly suggesting that the protein labeled in the rat striatum centered at approximately 58,000 Da was the dopamine-transport site. These data taken together demonstrate that the 58,000 Da protein has the same pharmacological characteristics and regional localization associated with the dopamine transporter. Other laboratories have solubilized other neurotransmitter transporters such as those for GABA (Radian et al., 1986) and serotonin (Rehavi et al., 1982; Habert et al., 1986).

To further elucidate some of the biochemical properties of the dopamine-transport site, photolabeled proteins were adsorbed onto wheat germ agglutinin and were specifically eluted from the lectin with the appropriate sugar. Since wheat germ agglutinin recognizes and binds to $N$-acetylglucosamine residues 
as well as terminal sialic acid residues on carbohydrate chains (Goldstein et al., 1965; Bhavanandan and Katlic, 1979), these data indicate that the dopamine transporter (or the portion of the transport complex that was photolabeled) contained either sugars of the N-linked type or terminal sialic acid residues. Further studies are required in order to determine the exact nature and amount of glycosylation of the dopamine-transport site.

In summary, we have described a novel iodinated photoaffinity ligand ( ${ }^{125}$ I-DEEP) that can specifically label the dopamine transporter or some component of it. This protein has an apparent molecular weight of about 58,000 $\mathrm{Da}$ and has all the pharmacological and biochemical characteristics of the wellestablished dopamine-transporter site previously described. The protein appears to exist in a glycosylated form, and further work is necessary for fully characterizing the type and extent of glycosylation. As a photoaffinity ligand, ${ }^{125}$ I-DEEP should prove to be a useful tool in the further characterization, isolation, and purification of the dopamine transporter.

\section{References}

Amlaiky, N., and M. G. Caron (1985) Communication: Photoaffinity labeling of the $\mathrm{D}_{2}$ dopamine receptor using a novel high-affinity radioiodinated probe. J. Biol. Chem. 260: 1983-1986.

Andersen, P. H. (1987) Biochemical and pharmacological characterization of ['H]GBR-12935 binding in vitro to rat striatal membranes: Labcling of the dopamine uptake complex. J. Neurochem. 48: $1887-$ 1896.

Andersen, P. H., J. Aas Jansen, and E. B. Nielsen (1987) ['H]GBR12935 binding in vivo in mouse brain: Labelling of a piperazine acceptor site. Eur. J. Pharmacol. 144: 1-6.

Benmansour, S., J.-J. Bonnet, P. Protais, and J. Costentin (1987) Sodium independence of the binding of $\left[{ }^{3} \mathrm{H}\right] \mathrm{GBR}-12783$ and other dopamine uptake inhibitors to the dopaminc uptake complex. Neurosci. Lett. 77: 97-102.

Berger, P., A. Janowsky, F. Vocci, P. Skolnik, M. M. Schweri, and S. M. Paul (1985) [ $\left.{ }^{3} \mathrm{H}\right]$ GBR-12935: A specific high affinity ligand for labeling the dopamine transport complex. Eur. J. Pharmacol. 107: 289-290.

Bhavanandan, V. P., and A. Katlic (1979) The interaction of wheat germ agglutinin with sialoglycoproteins. The role of sialic acid. J. Biol. Chem. 254: 4000-4008.

Bonnet, J. J., and J. Costentin (1986) GBR-12783. A potent and selective inhibitor of dopamine uptake: Biochemical studies in vivo and ex vivo. Eur. J. Pharmacol. I2I: 199-209.

Bonnet, J. J., P. Protais, A. Chagraoui, and J. Costentin (1986) High affinity ${ }^{3} \mathrm{H}$-GBR-12783 binding to a specific site associated with the neuronal dopamine uptake complex in the central nervous system. Eur. J. Pharmacol. 126: 211-222.

Chagraoui, A., J.-J. Bonnet, P. Protais, and J. Costentin (1987) In vivo binding of [ $\left.{ }^{3} \mathrm{H}\right] \mathrm{GBR}-12783$, a selective dopamine uptake inhibitor, in mouse striatum. Neurosci. Lett. 78: 175-179.

Goldstein, I. J., C. E. Hollerman, and E. E. Smith (1965) The lectins: Carbohydrate binding proteins of plants and animals. Biochemistry 4: $876-883$

Grigoriadis, D., H. B. Niznik, and P. Seeman (1988) Glycoprotein nature of $\mathrm{D}_{2}$ dopamine receptors. FEBS Lett. 227: 220-224.

Habert, E., D. Graham, and S. Z. Langer (1986) Solubilization and characterization of the 5-hydroxytryptamine transporter complex from rat cerebral cortical membranes. Eur. J. Pharmacol. 18: 197-204.

Heikkila, R. E., and L. Manzino (1984) Behavioral properties of GBR12909, GBR-1 3069 and GBR-1 3098: Specific inhibitors of dopamine uptake. Eur. J. Pharmacol. 103: 241-248.

Hess. H. J., R. M. Graham, and C. J. Homcy (1983) Photoaffinity

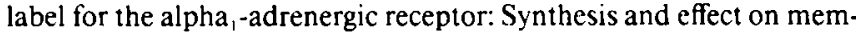

brane and affinity purified receptors. Proc. Natl. Acad. Sci. USA 80 2102-2106.

Horn, A. S. (1978) Characteristics of neuronal dopamine uptake. Adv. Biochem. Psychopharmacol. 19: 25-34.

Iversen, L. L. (1973) Catecholamine uptake processes. Br. Med. Bull. 29: $130-135$

Janowsky, A., P. Berger, F. Vocci, R. Labarca, P. Skolnick, and S. M. Paul (1986) Characterization of sodium-dependent $\left[{ }^{3} \mathrm{H}\right] \mathrm{GBR}-12935$ binding in brain: $A$ radioligand for selcctive labeling of the dopamine transport complex. J. Neurochem. 46: 1272-1276.

Javitz., J. A., R. O. Blaustein, and S. H. Snyder (1983) ['H]Mazindol binding associated with neuronal dopamine uptake sites in corpus striatum membranes. Fur. J. Pharmacol. 90:461-462.

Kilbourn, M. R. (1988) In vivo binding of $\left[{ }^{8} \mathrm{~F}\right] \mathrm{GBR}-13119$ to the brain dopamine uptake system. Life Sci. 42:1347-1353.

Kuhar, M. J. (1973) Neurotransmitter uptake: A tool in identifying neurotransmitter-specific pathways. Life Sci. 13: 1623-1634.

Laemmli, U. K. (1970) Cleavage of structural proteins during the assembly of the head of bacteriophage T4. Nature 227: $680-685$.

Leeb-Lundberg, L. M. F., K. E. G. Dikinson, S. L. Heald, J. E. S. Wikberg, P. O. Hagen, J. F. Debernardis, M. Winn. D. L. Andersen, R. J. Lefkowitz, and M. G. Caron (I 984) Photoaffinity labeling of mammalian alpha,-adrenergic receptors: Identification of the ligand binding subunit with a high affinity radioiodinated probe. J. Biol. Chem. 259: 10909-10915.

Lew, J. Y. E. Meller, and M. Goldstein (1985) Photoaffinity labeling and purification of solubilized $\mathrm{D}_{2}$ dopamine receptors. Eur. J. Pharmacol. 113: 145-146.

Lowry, O. H., N. J. Rosebrough, A. L. Farr, and R. J. Randall (1951) Protein measurement with the folin reagent. J. Biol. Chem. 193:265275.

Munson. P. J., and D. Rodbard (1980) LIGAND: A versatilc approach for characterization of ligand-binding systems. Anal. Biochem. 107 220-239.

Niznik, H. B., D. Grigoriadis, and P. Seeman (1986) Photoaffinity labeling of dopamine $\mathrm{D}_{2}$ receptors by $\left[{ }^{3} \mathrm{H}\right]$-azidomethylspiperone. FEBS Lett. 201: 71-76.

Radian, R., A. Bendahan, and B. I. Kanner (1986) Purification and identification of the functional sodium-and chloride-coupled $\alpha$-aminobutyric acid transport glycoproteins from rat brain. J. Biol. Chem. 261: 15437-15441.

Raiteri, M., F. Cerrito, A. M. Cervoni, R. del Carmine, M. T. Ribera, and $G$. Levi (1978) Studies on dopamine uptake and release in synptosomes. Adv. Biochem. Psychopharmacol. 19: 35-56.

Redouane, K., P. Sokoloff, J. C. Schwart/, P. Hamdi, A. Mann, C. G. Wermuth, J. Roy, and J. L. Morgat (1985) Photoaffinity labeling of D-2 dopamine binding subunits from rat striatum, anterior pituitary and olfactory bulb with a new probe $\left[{ }^{3} \mathrm{H}\right]$ azidosulpiride. Biochem. Biophys. Res. Commun. 130: 1086-1092.

Rehavi, M., P. Skolnick, and S. M. Paul (1982) Solubilization and partial purification of the high affinity $\left[{ }^{3} \mathrm{H}\right]$ imipramine binding site from human platclets. FEBS Lett. 150: 514-518.

Ritz, M. C., R. J. Lamb, S. R. Goldberg, and M. J. Kuhar (1987) Cocaine receptors on dopamine transporters are related to self-administration of cocaine. Science 237: 1219-1223.

Sharkey, J., M. C. Ritz, and M. J. Kuhar (1987) The cocaine binding site associated with dopamine uptake inhibition as labeled by ${ }^{3} \mathrm{H}$ GBR 12935. Soc. Neurosci. Abstr. 13: 144.

Snyder, S. H. (1970) Putative neurotransmitter in the brain: Selective neuronal uptake, subcellular localization and interactions with centrally acting drugs. Biol. Psychiatry 2: 367-389.

Stiles, G. L., M. G. Caron, and R. J. Lefkowitz (1984) $\beta$-adrenergic receptors: Biochemical mechanisms of physiological regulation. Physiol Rev. 64: 661-743.

van der Zee, P., H. S. Koger, J. Gootjes, and W. Hespe (1980) Aryl 1.4-dialk(en)ylpiperazines as selective and very potent inhibitors of dopamine uptake. Eur. J. Med. Chem. 15: 363-370.

Wilson, A. A., R. F. Dannals. H. T. Raver, H. D. Burns, and H. N. Wagner, Jr. (1986) I-125 and I-123 labelled iodobenzyl bromide, a useful alkylating agent for radiolabelling biologically important moleculacs. J. Labelled Comp. Radiopharm. 23: 83-93. 